\title{
Hybrid identification and genetic variation of Elymus sibiricus hybrid populations using EST-SSR markers
}

\author{
Xuhong Zhao, Junchao Zhang, Zongyu Zhang, Yanrong Wang and Wengang Xie*
}

\begin{abstract}
Background: Elymus sibiricus is an important native grass in Qinghai-Tibetan Plateau. Seed shattering is a serious problem for E. sibiricus, especially at harvest time. Cross breeding is an effective way to create new varieties with beneficial characteristic or improved traits, and to broaden genetic base.

Results: In this study, we created five hybrid populations by crossing seven E. sibiricus genotypes that have seed shattering variation. Then, nine EST-SSR primers were used for hybrid identification based on DNA fingerprinting, and genetic diversity analysis of hybrid populations and their respective parents. A total of 15 hybrids were identified. An analysis of amplified polymorphic bands among genuine hybrids and their respective parents revealed mainly two types of markers: 1) hybrids shared bands exclusively amplified in both parents; 2)hybrids shared bands exclusively amplified in male parents. For each hybrid population, the total number of amplified bands ranged from 37 to 57, the percentage of polymorphism varied from $65.12 \%$ to $75.68 \%$, with an average of $70.51 \%$. Novel bands found in each hybrid population varied from 0 to 9 bands, suggesting an occurrence of rearrangements in the hybrid population. The structure analysis revealed that all hybrid populations and parents were assigned to eight groups. The principal coordinate analysis (PCOA) showed similar results.
\end{abstract}

Conclusions: In general, this study proved EST-SSR markers are efficient for hybrid identification, and suggested more genetic variation could be captured in hybrid populations by crossing breeding.

Keywords: Elymus sibiricus, EST-SSR marker, Hybrid identification, Genetic diversity

\section{Background}

Elymus sibiricus L., named also siberian wild rye, is a perennial, caespitose, gramineous Elymus forage grass [1], indigenous to Northern Asia [2]. Its natural geographic distribution extends from Sweden to Japan and even to parts of Alaska and Canada [3]. It is wildly utilized in cultivated pasture and natural grassland in north China, owing to its excellent tolerance to low temperature and drought, and good forage quality and palatability [4].

In recent years, overgrazing and climate change resulted in grassland degeneration, it has created a need for revegetation/restoration of rangeland ecosystems in

\footnotetext{
* Correspondence: xiewg@|zu.edu.cn

The State Key Laboratory of Grassland Agro-ecosystems, Key Laboratory of Grassland Livestock Industry Innovation, Ministry of Agriculture, College of Pastoral Agriculture Science and Technology, Lanzhou University, Lanzhou 730020, People's Republic of China
}

north China. As a native grass in north China, E.sibiricus have the potential to be used in degenerated grassland due to its good adaptability to local environment. However, few E.sibiricus cultivars are available for revegetation /restoration projects in these regions. Until now, progress in cultivar development and improvement in E.sibiricus has seriously lagged behind crop plants even other forage grasses. In the last 20 years, only 6 cultivars have been developed from wild materials [5]. Meanwhile, this species has serious problem with seed shattering. In previous study, we have identified some low seed shattering genotypes from wild E.sibiricus germplasm originated from northeastern Qinghai-Tibet Plateau [4]. These materials are valuable genetic resources for seed shattering improvement in future breeding program. Cross breeding is an effective way to create new varieties with beneficial characteristic or improved traits, and to broaden genetic base of E. sibiricus [6]. Generally, these 
resynthesized breeding materials are genetically diverse from inbred line/cultivar [7], and might have higher heterosis than their parents [8]. Traditionally, we identify hybrids and analyze genetic diversity through morphological traits such as plant height, inflorescence, leaf shape, etc. The process of identification is time-consuming, and the accuracy of morphological identification is also limited due to the influence of environment factors. Compared to conventional hybrid identification through morphological difference in the course of plant breeding, marker-assisted selection (MAS) is more efficient way as it is reproducible, reliable, and independent from environmental conditions, it therefore could be used to mirror directly genetic diversity [9].

Among the available molecular markers, SSRs (simple sequence repeats) or microsatellites, offer an important DNA marker system for hybrid purity testing because of their co-dominance, reproducibility, robustness, and multiallelic nature [10]. The characteristics of co-dominance give enormous advantages to SSR marker, which can be more clearly to present the band feature of parent plant and their offspring in plant breeding [11]. SSR markers have been widely used to assess hybrid purity in maize [12], rice [13], sunflower [14], cabbage [15], bunching onion [16], cauliflower [17] and some forage grasses like orchardgrass [18]. In addition, SSR markers have been successfully used to distinguish E. sibiricus and E. nutans originated from Qinghai-Tibet Plateau [19] and detect genetic diversity and variation of E. sibiricus accessions worldwide [20]. There are no previous reports of hybrid identification using ESTSSR markers. Genetic information on hybrid populations is limited in E.sibiricus.

In this study, we used EST-SSR markers to identify hybrid based on specially amplified DNA fingerprinting and analyze genetic diversity of five hybrid populations and their respective parents in E. sibiricus. This study will help lay a foundation for future $E$. sibiricus breeding program.

\section{Methods}

\section{Plant materials}

A total of seven E. sibiricus accessions and their offsprings were used in this study (Tables 1 and 2). These seven accessions had different geographical origins, they were genetically and morphological divergent. According to previous genetic diversity study these accessions were clustered to different groups based on SCoT markers [20]. In addition, their selection was also based primarily on several contrasting agronomic traits: seed shattering, plant height, panicle length, etc. E. sibiricus is not an endangered or protected species, thus, no permission was required for collecting these samples in China. Single genotype from each parental accession was used to generate the $F_{1}$ hybrids by hand pollination in June 2014. A total of $15 F_{1}$ individuals were derived from five pairs of cross (Table 2). $F_{1}$ seeds were harvested from the female parents in August 2014. The $F_{1}$ individuals were grown in a greenhouse at approximately $22{ }^{\circ} \mathrm{C}$ and a $16 \mathrm{~h}$ photoperiod until they were 8 weeks old. The $\mathrm{F}_{1}$ individuals were then transplanted to the field in the campus experimental station at Lanzhou University, Yuzhong, Gansu, China (103 $34^{\prime}$ E, 35 $34^{\prime}$ N). No any permissions were required to carry out field experiment. A total of $15 \mathrm{~F}_{1}$ plants were tested by EST-SSR markers to confirm their hybrid status.

\section{DNA extraction and PCR amplification}

Genomic DNA was extracted from parental plants and individual hybrid plant tissue using SDS (sodium dodecyl sulfate) method [21] (Shan et al., 2011). DNA quantity and quality were verified using a Nanodrop spectrophotometer (NanoDrop Products, Wilmington, DE, USA) and agarose gel electrophoresis. Finally, the DNA concentration was adjusted with $\mathrm{dd}_{2} \mathrm{O}$ to $25 \mathrm{ng} /$ $\mu \mathrm{L}$ and stored at $-20{ }^{\circ} \mathrm{C}$ prior to PCR amplification. A total of nine selected polymorphic EST-SSR primers were used for genotyping (Table 3). These primers had been used in a previous genetic diversity study in $E$. sibiricus [4]. The optimal reaction system for E.sibiricus was as follows: $2 \mu \mathrm{L} 25 \mathrm{ng} / \mu \mathrm{L}$ DNA, $7.5 \mu \mathrm{L} 2 \times$ Reaction Mix (Tiangen Beijing, China), $0.5 \mu \mathrm{L} 10 \mu \mathrm{M}$ forward primer, $0.5 \mu \mathrm{L} 10 \mu \mathrm{M}$ reverse primer, $0.2 \mu \mathrm{L}(2.5 \mathrm{U} / \mu \mathrm{L})$ Golden DNA Polymerase (Tiangen Beijing, China), and $4.3 \mu \mathrm{L}$ of sterile $\mathrm{ddH}_{2} \mathrm{O}$ in a total of $15 \mu \mathrm{L}$ reaction volume. PCR amplification was carried out as described by Xie et al. [4]. Then amplification fragments were

Table 1 The origin and morphological traits of parents used in this study

\begin{tabular}{llll}
\hline Parents & Status & Origin & Morphological characteristics \\
\hline Y1005-1 & Wild & Ruo ergai, Sichuan, China & High seed shattering \\
LQ03-1 & Wild & Luqu, Gansu, China & Medium seed shattering \\
PI 348916 & Wild & Alaska, United State & Low seed shattering, Late flowering \\
XH09-4 & Wild & Xiahe, Gansu, China & High seed shattering \\
ZhN06-1 & Wild & Zhuoni, Gansu, China & Low seed shattering \\
ZhN06-11 & Wild & Zhuoni, Gansu, China & Low seed shattering, tall, long panicle \\
Chuancao No. 2 & Cultivar & Hongyuan, Sichuan, China & Tall, early flowering, medium seed shattering \\
\hline
\end{tabular}


Table 2 Parents and hybrid populations used in this study

\begin{tabular}{llll}
\hline Population & Female parents & Male parents & $\mathrm{F} 1$ individuals \\
\hline 1 & ZhN06-1 & Y1005-1 & $1-\mathrm{H} 1$ \\
2 & Y1005-1 & ZhN06-11 & 2-H2, 2-H3, 2-H4, 2-H5 \\
3 & ZhN06-11 & Y1005-1 & $3-\mathrm{H} 1,3-\mathrm{H} 2$ 3-H3, 3-H4, 3-H5 \\
4 & XH09-4 & LQ03-1 & $4-\mathrm{H} 1,4-\mathrm{H} 2,4-\mathrm{H} 3$ \\
5 & Chuancao No. 2 & Pl348916 & $5-\mathrm{H} 1,5-\mathrm{H} 2$ \\
\hline
\end{tabular}

separated on $6 \%$ denatured polyacrylamide gels. After electrophoresis, the gel was stained by $\mathrm{AgNO}_{3}$ solution. Then gel was photographed by a Gel Doc (TM) XY System (Bio-Rad, Hercules, CA, USA).

\section{Data analysis}

The amplified bands were scored as present (1) or absent (0), and only reproducible bands were considered. STRUCTURE v2.3.4 software was used to analyze the population structure of E. sibiricus accessions and hybrid populations, with the 'admixture mode', burn-in period of 10,000 iterations and a run of 100,000 replications of Markov Chain Monte Carlo (MCMC) after burn in [22]. For each run, 10 independent runs of STRUCTURE were performed with the number of clusters $(\mathrm{K})$ varying from 1 to 8 . Mean $\mathrm{L}(\mathrm{K})$ and delta $\mathrm{K}(\Delta \mathrm{K})$ were estimated using the method described by Evanno et al. [23] To detect genetic relationship among different accessions, a principal coordinate analysis (PCoA) was constructed based on Jaccard's genetic similarity matrix using DCENTER module in NTSYS (version 2.10), which is more informative regarding distances among major groups [24]. E. sibiricus hybrid identification was carried out according to a method used in orchardgrass [18]. Single primer pairs or primer combinations that were diagnostic for parental plants and hybrid plants were used.

\section{Results}

\section{EST-SSR marker transferability}

EST-SSR markers previously developed from Snake River wheatgrass (Elymus wawawaiensis), thick spike wheatgrass (Elymus lanceolatusd), bluebunch wheatgrass (Pseudoroegeneria spicata) and Leymus species were used in this study. Finally, a total of 9 primers were selected and used for hybrid identification and genetic diversity analysis, of which 3 from Elymus (Elw hereafter), 4 from Pseudoroegneria (Ps hereafter) and 2 from Leymus (Lt hereafter). The results proved that all 9 primers can be successfully amplified across 22 E.sibiricus plants used in this study, with $100 \%$ the transferability rate.

\section{Hybrid identification}

Single primers or primer combinations that were diagnostic for parental plants and hybrid plants were used. In the study, an analysis of amplified polymorphic bands among genuine hybrids and their respective parents mainly revealed two types of markers: 1) hybrids shared bands exclusively amplified in both parents (Fig. 1a); 2) hybrids shared bands exclusively amplified in male parents (Fig. 1b); Finally, according to this method, 15 hybrids were successfully identified using different primers and then used for the genetic diversity analysis (Table 2).

\section{EST-SSR polymorphism and genetic relationship in hybrid populations and parents}

In this study, 9 primers were used for genetic diversity analysis among five hybrid populations and their parents (Table 4). The total number of amplified bands ranged from 37 (Pop 1) to 57(Pop 2, 3), the percentage of polymorphism varied from 65.12 (Pop 5) to $75.68 \%$ (Pop 1), with an average of $70.51 \%$.

Regarding the parental origin of the amplified bands inherited by hybrid populations, similar percentage of parental origin were found in three hybrid populations. The percentages in the first three populations didn't

Table 3 The 9 EST-SSR primers used in this study

\begin{tabular}{lll}
\hline Primer name & Forward primers & Reverse primers \\
\hline Elw1420s081 & GGATAGACCCATGAGCTGACTCACAAGTTGAACACAACA \\
Elw3545s194 & CAGCACTAGTATCCACCTCCACCT & TGTTACAGCCTCTTCAGGCTCTTC \\
Elw5627s404 & AGATGAAGCTGGTAACCGAGACAG & ATTCCTCTAATGGAAGCTCTGGC \\
Ps1830 & GACTCGGCGAAAGGACTCTCT & CTCGACGTCCTTCATGAGCTT \\
Ps2283 & GCCACAACAAGAGAAGACCTTGC & GACCTGCATGATGCTCTCGC \\
Ps3577 & CATCTTGCATATAGCTCCTTCGCT & CTCAAGAAACCCACAATCCAATTC \\
Ps938 & TTGCTCCTATGGTCCACGTAGTT & AAAGTGAATTCTGCCATCAGAGC \\
Ltc0055 & AAGAAGAAGAGGCCGAGGAATAAA & CGTGGATGTGCTGCAGGTAGTA \\
Ltc0157 & GCAATGAACACTGAATCAATCGAG & CGTGTGAGACTCATCGATGTACC \\
\hline
\end{tabular}




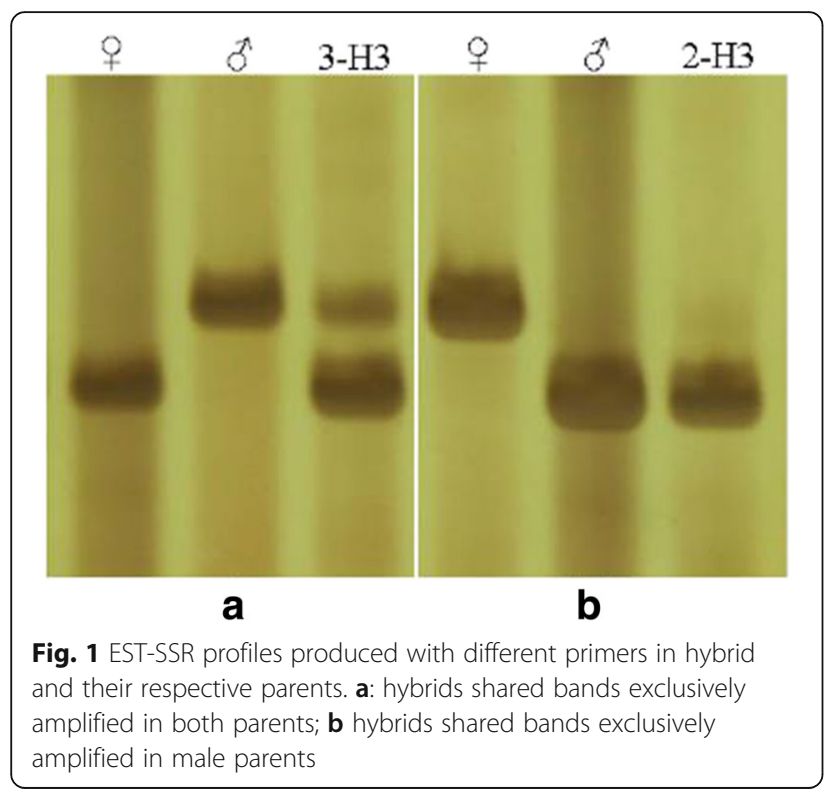

reach $50 \%$. For example, in the population 1, 32.43\% were inherited from ZhN06-1 and 32.43\% were from Y1005-1. In the population 2, 47.37\% were from ZhN0611 and Y1005-1 had $42.11 \%$ origin. In the population 3, $38.59 \%$ were inherited from male parent and 35.09\% from female parent. However, in the population 4 and 5 , $56.09 \%$ and $55.81 \%$ amplified bands were inherited from male parents, respectively. Some types of polymorphism evidenced an occurrence of rearrangements in the hybrid populations that resulted from the gain of novel bands (not seen in parental genomes). Total number of bands that exclusively present in hybrid populations ranged from 0 (Pop4) to 9 (Pop2), with an average of 6.2.

The population structure of hybrid populations and their parents was analyzed in this study. Based on maximum likelihood and delta $\mathrm{K}(\Delta \mathrm{K})$ values, the number of optimum groups was eight (Fig. 2). All accessions were assigned to eight groups. group1 included LQ03-1, 1-H1, 2-H2, 2-H3, 2-H5; group 2: PI348916, 2-H4, 3-H4, 3-H5; group 3: ZhN06-11, 3-H1, 3-H2; group 4: 4-H2, 4-H3; group 5: 3-H3; group 6: ZhN06-1, Chuancao No.2, 5-H1, 5-H2; group 7: XH09-4, 4-H1; group 8: Y1005-1. Every group was mixed genetic ingredient of other groups in different extent. Especially, LQ03-1, PI348916, ZhN06-11, 3$\mathrm{H} 3,1-\mathrm{H} 1$ and 2-H5 had more complicated genetic constitutes than the other accessions in the study. 1-H1, 2-H5 and $3-\mathrm{H} 3$ were the $\mathrm{F}_{1}$ individuals from population 1,2 and 3, respectively. However, some accessions presented a purer genetic ingredient within their groups. 4-H1, 5- H1 and $5-\mathrm{H} 2$, the $\mathrm{F}_{1}$ plant of population 4 and 5 , had same genetic constitutes to female XH09-4 and Chuancao No.2 respectively. The rest of individuals for pure genetic
Table 4 EST-SSR results achieved in hybrid populations and their parents

\begin{tabular}{|c|c|c|c|c|c|c|c|c|}
\hline Population & Primer & $\mathrm{T}$ & M & TP & MF1 & FF1 & EF1 & PPB (\%) \\
\hline \multirow[t]{7}{*}{1} & Elw1420s081 & 3 & 0 & 3 & 0 & 1 & 0 & 100.00 \\
\hline & Elw3545s194 & 3 & 3 & 0 & 3 & 3 & 0 & 0.00 \\
\hline & Elw5627s404 & 14 & 0 & 14 & 3 & 2 & 6 & 100.00 \\
\hline & Ps3577 & 4 & 2 & 2 & 2 & 2 & 1 & 50.00 \\
\hline & Ps938 & 7 & 1 & 6 & 1 & 1 & 0 & 85.71 \\
\hline & Ltc0055 & 6 & 3 & 3 & 3 & 3 & 0 & 50.00 \\
\hline & Total & 37 & 9 & 28 & 12 & 12 & 7 & 75.68 \\
\hline \multirow[t]{10}{*}{2} & Elw1420s081 & 6 & 1 & 5 & 1 & 1 & 4 & 83.33 \\
\hline & Elw3545s194 & 3 & 1 & 2 & 1 & 2 & 0 & 66.67 \\
\hline & Elw5627s404 & 14 & 2 & 12 & 4 & 5 & 3 & 85.71 \\
\hline & Ps1830 & 9 & 4 & 5 & 5 & 5 & 0 & 55.56 \\
\hline & Ps2283 & 2 & 1 & 1 & 1 & 1 & 1 & 50.00 \\
\hline & Ps3577 & 4 & 2 & 2 & 3 & 2 & 0 & 50.00 \\
\hline & Ps938 & 5 & 2 & 3 & 5 & 2 & 0 & 60.00 \\
\hline & Ltc0055 & 3 & 3 & 0 & 3 & 3 & 0 & 0.00 \\
\hline & Ltc0157 & 11 & 3 & 8 & 4 & 3 & 1 & 72.73 \\
\hline & Total & 57 & 19 & 38 & 27 & 24 & 9 & 66.67 \\
\hline \multirow[t]{10}{*}{3} & Elw1420s081 & 5 & 1 & 4 & 1 & 1 & 3 & 80.00 \\
\hline & Elw3545s194 & 3 & 1 & 2 & 1 & 2 & 0 & 66.67 \\
\hline & Elw5627s404 & 14 & 1 & 13 & 5 & 2 & 3 & 92.86 \\
\hline & Ps1830 & 10 & 3 & 7 & 4 & 2 & 0 & 70.00 \\
\hline & Ps2283 & 2 & 1 & 1 & 1 & 1 & 1 & 50.00 \\
\hline & Ps3577 & 4 & 2 & 2 & 3 & 3 & 0 & 50.00 \\
\hline & Ps938 & 5 & 1 & 4 & 1 & 2 & 0 & 80.00 \\
\hline & Ltc0055 & 3 & 3 & 0 & 3 & 3 & 0 & 0.00 \\
\hline & Ltc0157 & 11 & 3 & 8 & 3 & 4 & 1 & 72.73 \\
\hline & Total & 57 & 16 & 41 & 22 & 20 & 8 & 71.93 \\
\hline \multirow[t]{9}{*}{4} & Elw3545s194 & 2 & 2 & 0 & 2 & 2 & 0 & 0.00 \\
\hline & Elw5627s404 & 7 & 1 & 6 & 1 & 4 & 0 & 85.71 \\
\hline & Ps1830 & 7 & 2 & 5 & 2 & 6 & 0 & 71.43 \\
\hline & Ps2283 & 3 & 1 & 2 & 1 & 2 & 0 & 66.67 \\
\hline & Ps3577 & 8 & 1 & 7 & 2 & 3 & 0 & 87.50 \\
\hline & Ps938 & 6 & 0 & 6 & 0 & 1 & 0 & 100.00 \\
\hline & Ltc0055 & 3 & 3 & 0 & 3 & 3 & 0 & 0.00 \\
\hline & Ltc0157 & 5 & 1 & 4 & 1 & 2 & 0 & 80.00 \\
\hline & Total & 41 & 11 & 30 & 12 & 23 & 0 & 73.17 \\
\hline \multirow[t]{10}{*}{5} & Elw1420s081 & 3 & 0 & 3 & 0 & 1 & 0 & 100.00 \\
\hline & Elw3545s194 & 3 & 3 & 0 & 3 & 3 & 0 & 0.00 \\
\hline & Elw5627s404 & 6 & 0 & 6 & 0 & 3 & 1 & 100.00 \\
\hline & Ps1830 & 8 & 2 & 6 & 2 & 3 & 2 & 75.00 \\
\hline & Ps2283 & 3 & 0 & 3 & 1 & 1 & 1 & 100.00 \\
\hline & Ps3577 & 4 & 2 & 2 & 2 & 2 & 0 & 50.00 \\
\hline & Ps938 & 4 & 1 & 3 & 1 & 2 & 2 & 75.00 \\
\hline & Ltc0055 & 4 & 4 & 0 & 4 & 4 & 0 & 0.00 \\
\hline & Ltc0157 & 8 & 3 & 5 & 3 & 5 & 1 & 62.50 \\
\hline & Total & 43 & 15 & 28 & 16 & 24 & 7 & 65.12 \\
\hline
\end{tabular}

$\mathrm{T}=$ Total number of amplified bands; $\mathrm{M}=$ Number of monomorphic bands; TP = Total number of polymorphic bands; MF1 = Bands shared by male parents and hybrids; FF1 = Bands shared by female parents and hybrids; EF1 = Bands exclusively present in hybrids; PPB = Percentage of polymorphic bands 

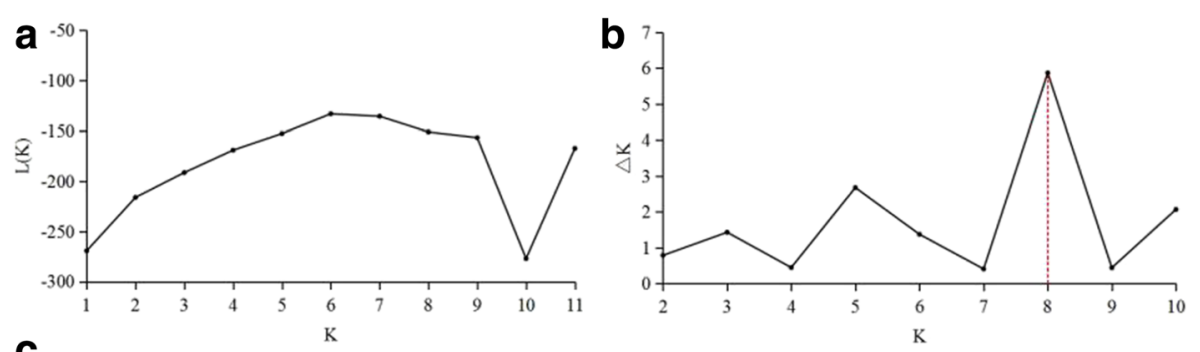

C

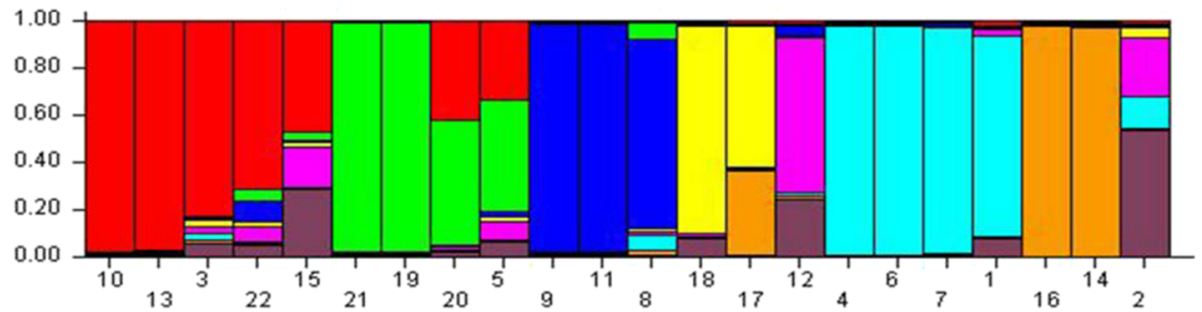

Fig. 2 Eight groups of 22 E. sibiricus accessions inferred from STRUCTURE analysis and the description of detected the optimum value of $\mathrm{K}$ by using graphical method. a Mean $\mathrm{L}(\mathrm{K})$ over 20 runs for each $\mathrm{K}$ value; $\mathbf{b}$ Maximum delta $\mathrm{K}(4 \mathrm{~K})$ values were used to determine the uppermost level of structure for $\mathrm{K}$ ranging from 2 to 10 , here $\mathrm{K}$ is 8 and eight clusters; $\mathbf{c}$ The vertical coordinate of each group indicates the membership coefficients for each accession. 1-22 represented respectively: ZhN06-1, Y1005-1, 1-H1, Chuancao No.2, PI348916, 5-H1, 5- H2, ZhNO6-11, 3-H1, 2-H2, $3-\mathrm{H} 2,3-\mathrm{H} 3,2-\mathrm{H} 3, \mathrm{XHO9-4,} \mathrm{LQO3-1,4-H1,} \mathrm{4-H2,} \mathrm{4-H3,} \mathrm{2-H4,} \mathrm{3-H4,} \mathrm{3-H5,} \mathrm{2-H5}$

constitutes included 2-H2, 2- $\mathrm{H} 3,2-\mathrm{H} 4,3-\mathrm{H} 1,3-\mathrm{H} 2$ and $3-\mathrm{H} 5$, they came from population 2 and 3.

The principal coordinate analysis (PCoA) showed about $64.72 \%$ of the total variation was described by the first three PCo (Fig. 3). The results of PCoA analysis were similar to structure analysis.

\section{Discussion}

\section{EST-SSR markers for hybrid identification}

Traditional hybrid identification depends on morphological traits like plant height, leaf shape, flower color, growth habit, and so on. But environmental factors often affect the accuracy of identification. DNA fingerprinting techniques

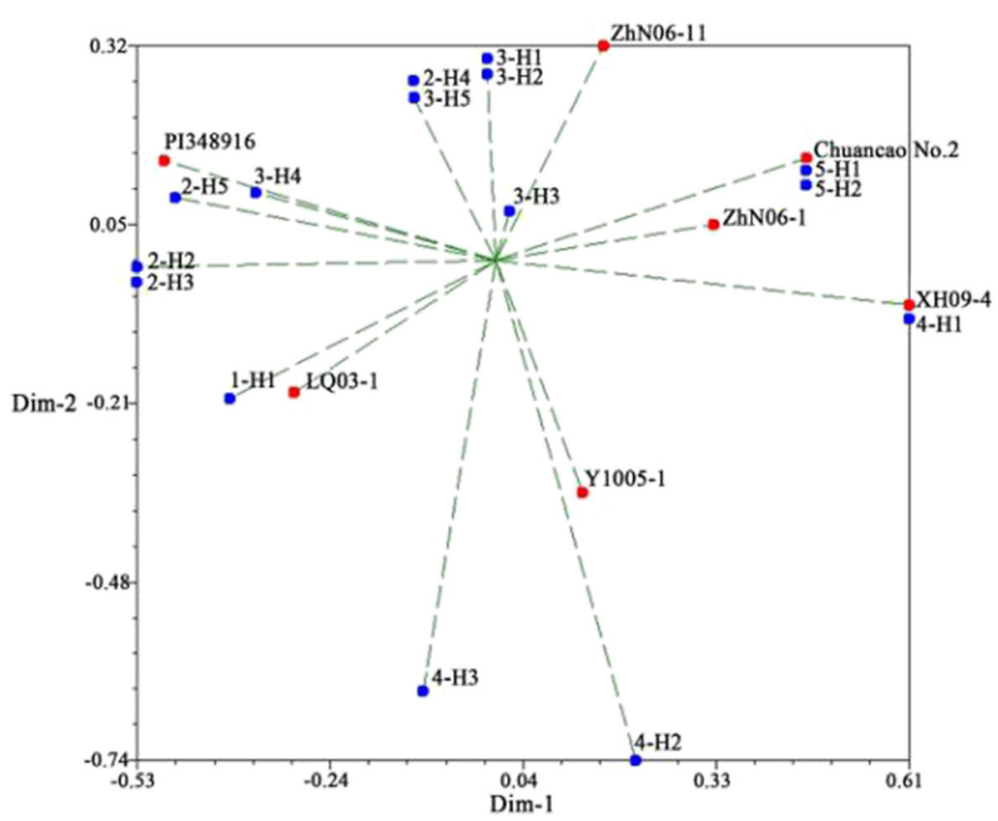

Fig. 3 Principal coordinates analysis for EST-SSR markers using genetic similarity matrix for 22 E. sibiricus accessions. Red dot and blue dot represented parents and hybrid populations, respectively 
are efficient alternatives to morphological identification, and make plant identification easy and accurate. Molecular markers have been successfully applied to identification of crop and forage grass species [25, 26]. EST-SSRs are codominant markers that can show evidently the heterozygosity of offspring populations by the bands from parents and hybrid plants [10,27]. Our study is the first report of $E$. sibiricus hybrids identification using EST-SSR markers. Based on our results single primers or primer combinations that were diagnostic for parental plants and hybrid plants could be used for hybrid identification. Fifteen hybrids were identified with two types of DNA fingerprinting. In general, this study demonstrated that EST-SSR markers can effectively identify E.sibiricus hybrids through special DNA fingerprinting profiles. This study will lay a foundation for E. sibiricus breeding in future.

\section{EST-SSR marker for genetic diversity in E. sibiricus}

EST-SSRs are highly polymorphic, abundant and are accessible to research laboratories via published primers sequences [4]. These published primers are especially important resources for species like E. sibiriucs with few molecular markers available. In this study, a total of 9 EST-SSR markers from three different genuses were used for hybrid identification and genetic diversity analysis. The transferability rate of EST-SSRs was $100 \%$. Results of this study were consistent with previous reports that EST-SSR markers have high transferability rate among species. Information on genetic diversity and hybrid population and their parents can improve our understanding of breeding materials.Based on our results the percentage of polymorphism varied from 65.12 (Pop 5) to $75.68 \%$ (Pop 1), with an average of $70.51 \%$. The average percentage of polymorphism (PPB) of five hybrid populations were lower than previous reports of SRAP $(\mathrm{PPB}=86.5 \%)$ [28], SSR $(\mathrm{PPB}=89.4 \%)$ [4], and SCoT $(\mathrm{PPB}=91.9 \%)$ [29]. The major reason for relatively low PPB could be small sample size of each population. In addition, hybrid populations derived from seven parent genotypes, and genetic base was relatively narrow. This can be supported by results of structure analysis. In general, these accessions and their offspring did not show major genetic structure, most of accessions were assigned into mixed groups, indicating relatively narrow genetic base.

\section{Broadening genetic diversity for breeding}

In this study, some types of polymorphism have evidenced potentially an occurrence of chromosome variation or gene rearrangements in hybrid populations that resulted from the gain of novel bands. The results of the present study suggested that more genetic diversity and new variation could be captured by crossing breeding. Whether these novel bands were responsible to new genes associated to seed shattering or other important traits, it was still not clear. It is still difficult to address particular mechanisms understanding the chromosomal or genomic rearrangements in response to novel bands. In the future, molecular markers combined with sequence data might provide evidence to the inheritance of transcribed regions and gene functions.

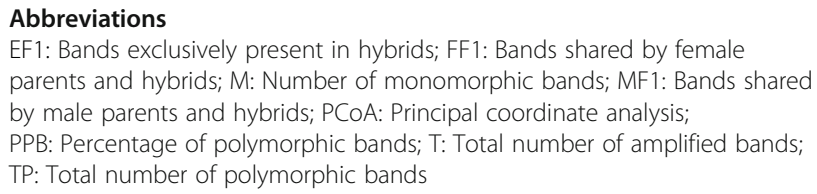

\section{Acknowledgements}

We thanks grants from the Program for Changjiang Scholars and Innovative Research Team in University (IRT-17R50), Chinese National Basic Research Program (973 Program) (No. 2014CB138704), the Open Project Program of State Key Laboratory of Grassland Agro-ecosystems, 111 program (B12002).

\section{Funding}

This study was supported by grants from the Chinese National Basic Research Program (973 Program) (No. 2014CB138704), the Open Project Program of State Key Laboratory of Grassland Agro-ecosystems, 111 program (B12002).

\section{Availability of data and materials}

The data supporting the conclusions of this article are included within the article.

\section{Authors' contributions}

WX, YW conceived and designed the experiments. XZ performed the experiments. ZZ and JZ provided help with data analysis. $X Z$ and $W X$ wrote and revised the manuscript. All authors have read and approved the final manuscript.

\section{Ethics approval and consent to participate}

Not applicable

Consent for publication

Not applicable

Competing interests

The authors declare that they have no competing interests.

\section{Publisher's Note}

Springer Nature remains neutral with regard to jurisdictional claims in published maps and institutional affiliations.

Received: 10 March 2017 Accepted: 28 November 2017

Published online: 12 December 2017

\section{References}

1. Lei YT, Zhao YY, Yu F, Li Y, Dou Q. Development and characterization of 53 polymorphic genomic-SSR markers in Siberian wild rye (Elymus sibiricus L.). Conserv Genet Resour. 2014;6:861-4.

2. Ma X, Chen SY, Zhang XQ, Bai SQ, Zhang CB. Assessment of worldwide genetic diversity of Siberian wild rye (Elymus sibiricus L.) germplasm based on gliadin analysis. Molecules. 2012;17:4424-34.

3. Bowden WM, Cody WJ. Recognition of Elymus sibiricus L. from Alaska and the district of Mackenzie. Bull Torrey Bot. Club. 1961;88:153-5.

4. Xie WG, Zhao XH, Zhang JQ, Wang YR, Liu WX. Assessment of genetic diversity of Siberian wild rye (Elymus sibiricus L.) germplasms with variation of seed shattering and implication for future genetic improvement. Biochem Syst Ecol. 2015;58:211-8.

5. Yan JJ, Bai SQ, Ma X, Gan YM, Zhang JB. Genetic diversity of Elymus sibiricus and its breeding in China. Chin Bull Bot. 2007;24:226-31. 
6. Zhang ZY, Zhang JC, Zhao XH, Xie WG, Wang YR. Assessing and broadening genetic diversity of Elymus sibiricus germplasm for the improvement of seed shattering. Molecules. 2016;21(7):869.

7. Jesske T, Olberg B, Schierholy A, Becker HC. Resynthesized lines from domesticated and wild Brassica taxa and their hybrids with B. napus L.: genetic diversity and hybrid yield. Theor Appl Genet. 2013;126:1053-65.

8. Shen JX, Fu TD, Yang GS. Relationship between hybrid performance and genetic diversity based on SSRs and ISSRs in Brassica napus L. Agr Sci China. 2003;2:1083-90

9. Madesis P, Abraham EM, Kalivas A, Ganopoulos I, Tsaftaris A. Genetic diversity and structure of natural Dactylis glomerata L. populations revealed by morphological and microsatellite-based (SSR/ISSR) markers. Genet Mol Res. 2014;13:4226-40.

10. Lalit A, Manjusha V, Suman L. Diagnostic set of microsatellite markers for hybrid purity testing and molecular identification of hybrids and parental lines in sorghum. J Plant Res. 2014;1:1-4.

11. Zhao YF, Zhang XQ, Ma X, Xie WG, Huang LK. Morphological and genetic characteristics of hybrid combinations of Dactylis glomerata. Genet Mol Res. 2014;13:2491-503.

12. Daniel IO, Adetumbi JA, Oyelakin O, Olakojo SA, Ajala MO, Onagbesan SO. Application of SSR markers for genetic purity analysis of parental inbred lines and some commercial hybrid maize (Zea mays L.). Am J Exp Agri. 2012;2:597-606.

13. Sundaram RM, Naveenkumar B, Biradar SK, Balachandran SM, Mishra B, IlyasAhmed M, et al. Identification of informative SSR markers capable of distinguishing hybrid Rice parental lines and their utilization in seed purity assessment. Euphytica. 2008;163:215-24.

14. Iqbal A, Sadaqat HA, Khan AS, Amjad M. Identification of sunflower (Helianthus annuus, Asteraceae) hybrids using simple-sequence repeat markers. Genet Mol Res. 2010;10:102-6.

15. Liu LW, Liu G, Gong YQ, Dai WH, Wang Y, Yu FM, et al. Evaluation of genetic purity of $F_{1}$ hybrid seeds in cabbage with RAPD, ISSR, SRAP, and SSR markers. Hortscience. 2007;2:724-7.

16. Tsukazaki H, Fukuoka H, Song YS, Yamashita K, Wako T, Kojima A. Considerable heterogeneity in commercial F1 varieties of bunching onion (Allium fistulosum) and the proposal of a breeding scheme for conferring genetic traceability using SSR markers. Breeding Sci. 2006;56:321-6.

17. Zhao Z, Gu H, Sheng X, Yu H, Wang J, Cao J. Genetic purity testing of loosecurd cauliflower hybrids using SSR markers and grow out test. Seed Sci Technol. 2012;40:209-14.

18. Xie $W G$, Zhang $X Q$, Cheng $Y X$. Identification and genetic variation analysis of Orchardgrass hybrids (Dactylis glomerata) by SSR molecular markers. Acta Pratac Sin. 2010;19:212-7.

19. Lei YT, Dou QW. Distinguishing Elymus nutans from Elymus sibiricus in Qinghai - Tibet plateau using a SSR marker. Pratac Sci. 2012;29:937-42.

20. Xie WG, Zhang JC, Zhao XH, Zhang JQ, Wang YR. Siberian wild rye ( Elymus sibiricus, I.): genetic diversity of germplasm determined using DNA fingerprinting and SCOT markers. Bioch Syst Ecol. 2015;60:186-92.

21. Shan Z, Wu HL, Li CL, Chen H, Wu Q. Improved SDS method for general plant genomic DNA extraction. Guangdong Agri Sci. 2011;8:113-5.

22. Pritchard JK, Stephens M, Donnelly P. Inference of population structure from multilocus genotype data. Genetics. 2000;155:945-59.

23. Evanno G, Regnaut $\mathrm{S}$, Goudet J. Detecting the number of clusters of individuals using the software structure: a simulation study. Mol Ecol. 2005; 14:2611-20.

24. Rohlf FJ. NTSYS-pc: numerical taxonomy and multivariate analysis system. New York, NY, USA: Exeter Software; 1992

25. Cabo SL, Carvalho A, Martins LP, Martín A, Lima-Brito JE. Potential of start Codon targeted (SCOT) markers for DNA fingerprinting of newly synthesized tritordeums and their respective parents. J Appl Genet. 2014;55:307-12.

26. Huang LK, Huang X, Yan HD, Yin GH, Zhang XQ, Tian Y, et al. Constructing DNA fingerprinting of Hemarthria cultivars using EST-SSR and SCOT markers. Genet Resour Crop Ev. 2014;61:1047-55.

27. Powell W, Machray GC, Jim P. Polymorphism revealed by simple sequence repeats. Trends Plant Sci. 1996;7:215-22.

28. Yan JJ, Bai SQ, Zhang XQ, You MH, Zhang CB, Li DX, et al. Genetic diversity of wild Elymus sibiricus germplasm from the Qinghai-Tibetan plateau in China detected by SRAP markers. Acta Pratac Sin. 2010;19:173-83.

29. Zhang JC, Xie WG, Wang YR, Zhao XH. Potential of start Codon targeted (SCOT) markers to estimate genetic diversity and relationships among Chinese Elymus sibiricus accessions. Molecules. 2015;20:5987-6001.

\section{Submit your next manuscript to BioMed Central and we will help you at every step:}

- We accept pre-submission inquiries

- Our selector tool helps you to find the most relevant journal

- We provide round the clock customer support

- Convenient online submission

- Thorough peer review

- Inclusion in PubMed and all major indexing services

- Maximum visibility for your research

Submit your manuscript at www.biomedcentral.com/submit
C Biomed Central 